\title{
Analysis of maxillofacial fractures pattern in a tertiary hospital of Bangladesh: A retrospective study of 329 cases
}

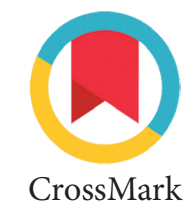

\author{
AFM S. Rahman, ${ }^{1 *}$ Ismat A. Haider, ${ }^{2}$ Md. HUr. Rashid²
}

\section{Abstract}

Objective: The purpose of this retrospective study was to reveal the pattern of maxillofacial fractures in a tertiary hospital of Bangladesh. Materials and Methods: A sum of 329 cases with maxillofacial trauma was treated in the inpatient department of Oral and Maxillofacial Surgery of Dhaka Dental College Hospital from January 2016 to December 2018. The outcome variables included age, gender, etiology, and anatomic site of fractures.

Results: The age range was 4 - 82 years with peak frequency occurring in the age group 21-30 years. The mean age was $28.08 \pm 14.77$ (Mean \pm SD) years. The male to female ratio was 4.98: 1 . We observed that, $80.85 \%$ cases encountered from road traffic accidents (RTAs) followed by assault (8.51\%). The mandible (61.7\%) was predominantly affected bone followed by zygomatic complex (9.71\%), midface $(9.42 \%)$. The body
(35.78\%) was the commonest site of mandibular fracture followed by the parasymphysis (23.32\%), angle (17.57\%), and condyle (14.07\%). The least affected site was the ramus $(0.4 \%)$ and the coronoid (0.64\%) process. In midface fractures, the zygomaticomaxillary complex (ZMC) was the most susceptible area (25.40\% of midface) followed by maxilla (24.60\%). In a nutshell, the incidence of mandibular and zygomatic complex fractures was predominant among maxillofacial fractures.

Conclusion: Young men were predominantly affected in maxillofacial trauma, as they were involved in outside activities mostly. Road traffic rules should be strictly implemented. Awareness of safety guidelines should be executed by campaigning. In a nutshell, the incidence of mandibular and zygomatic complex fractures was predominant among all the maxillofacial fractures.
'Department of Oral and Maxillofacial Surgery, Rajshahi Medical College, Bangladesh ${ }^{2}$ Department of Oral and Maxillofacial Surgery, Dhaka Dental College and Hospital, Bangladesh

*Correspondence to: AFM S. Rahman, Department of Oral and Maxillofacial Surgery, Rajshahi Medical College, Bangladesh

raselblackpearl@gmail.com, drraseloms@gmail.com

Received: 24 December 2020

Revised: 20 April 2020

Accepted: 23 July 2021

Available Online: 1 December 2021

Keywords: Maxillofacial Fractures, Pattern, Road traffic accident, Trauma Cite this Article: Rahman AFMS, Haider IA, Rashid MH. 2021. Analysis of maxillofacial fractures pattern in a tertiary hospital of Bangladesh: A retrospective study of 329 cases. Journal of Dentomaxillofacial Science 6(3): 164-168. D0I: 10.15562/jdmfs.v6i3.1129

\section{Introduction}

Trauma is the major etiologic factor of mortality in the first four decades of life. Almost one million deaths with approximately 15 to 20 million injuries are occurred per year in road traffic accidents (RTAs), as reported by the World Health Organization. ${ }^{1}$ The face is susceptible to trauma as it is the most exposed part of the body. ${ }^{2}$ There are several reasons for maxillofacial trauma accounted for all over the world such as RTAs, falls from height, interpersonal violence, sports injuries, and industrial trauma. ${ }^{3}$ The etiologies of injury influence the severity and variety of maxillofacial fractures. ${ }^{4}$ RTAs are reported to be a predominant cause of maxillofacial trauma in rising countries. On the other hand, inter-personal violence is predominant in developed nations. ${ }^{5}$ The mandibular fractures are predominant among maxillofacial fractures followed by the zygomaticomaxillary complex (ZMC), maxilla, and alveolar process. ${ }^{6}$ The parasymphysis region is affected mostly among the mandibular fracture followed by the body, angle, condylar, symphysis, and coronoid process. ${ }^{7}$ The age and gender of the patient are reported as significant aspects influencing the incidence of maxillofacial injuries. The peak prevalence of maxillofacial trauma is noticed in the 3rd decade of life. The frequency of maxillofacial trauma is seen in younger patients below 40 years of age. ${ }^{8}$ The age group above 60 years and under 5 years is less affected by maxillofacial trauma. Males are predominantly involved than females in maxillofacial injuries with a male to a female proportion of roughly $3: 1 .^{9}$

This retrospective cross-sectional study was conducted to evaluate the pattern of maxillofacial fracture in the inpatient department of Oral \& Maxillofacial Surgery of Dhaka Dental College and Hospital, Bangladesh.

\section{Material and Methods}

The present study was conducted in the Department of Oral and Maxillofacial Surgery, Dhaka Dental College Hospital, Dhaka, Bangladesh, during the three years from January 1016 to December 2018. We assembled data from departmental medical documentations. A sum of 329 patients' medical records was reviewed in the present study.

Study Design: Retrospective, cross-sectional, descriptive study. Study Location: Department of Oral and 
Maxillofacial Surgery of Dhaka Dental College Hospital, Bangladesh. Study Duration: From January 2016 to December 2018. Sample size: 329 patients.

Inclusion criteria: Patients of both sexes and all age groups; Clinically and radiographically diagnosed maxillofacial fractures cases; Patients were admitted to the inpatient department; Patients were managed by surgical intervention under general anesthesia.

Exclusion criteria: The exclusion of patients was done who had incomplete medical records. Study variables: Patient's age; Sex; Etiology of maxillofacial trauma (physical assaults, accidental falls, road traffic accident (RTA), and others); Site of maxillofacial fractures; Number of fractures (single/unilateral or multiple/bilateral)

Data collection procedure: In total, three hundred and twenty-nine patients with maxillofacial trauma were included in the present study during the three years study period. In our study, the patient's age ranged from 4-82 years. They were divided into eight different age groups for study purposes. Maxillofacial surgeons assessed patients by clinical examination and radiographic investigations. Radiographic assessment was done by conventional radiography, computed tomography (CT) scans. The maxillofacial fractures were classified according to sites such as the mandible, zygomaticomaxillary complex, orbital, Le-Fort (Le Fort I, Le Fort II and, Le Fort III), and naso-orbital-ethmoid (NOE), pan facial fracture. Mandibular fractures were detailed according to the sites like the symphysis, parasymphysis, body, angle, ramus, coronoid process, and the condylar process. Treatment modalities were broadly separated into two categories, one was open reduction and internal fixation (ORIF) and the other had been managed conservatively by closed treatment.

Data Analysis: The data were analyzed by utilizing SPSS version-22 windows software program. The Chi square teat was applied to find out statistical significance of categorical variables. The p-value of less than 0.05 was considered statistically significant.

\section{Results}

A total of 329 patients accounted for maxillofacial fractures in the three years duration of our study. The total number of maxillofacial fractures was 441 . In our study, the males were accounted roughly for $83 \%(n=274)$, whereas females $17 \%(n=55)$ with a male to female ratio of 4.98: 1 figure 1 .

Age and sex distribution: According to our study, the age of the patient at the time of injury ranged from 4 - 82 years, with a mean age (SD) of 28.08 years $( \pm 14.77)$. The highest incidence of maxillofacial trauma occurred in the age group of $21-30$ years $(n=103 ; 31.3 \%)$. The age-specific distribution in patients showed an increasing trend till the third decade with subsequent decreasing incidence with each new decade. 28 injuries (8.51\%) occurred in the first decade, 84 (25.53\%)

Table 1 Age and sex distribution among the study sample

\begin{tabular}{|c|c|c|c|c|c|c|}
\hline Age group & Male & Female & Total cases & Percentage (\%) & Mean \pm SD & $P$ value \\
\hline $0-10$ & 16 & 12 & 28 & 8.51 & & \\
\hline $11-20$ & 64 & 20 & 84 & 25.53 & & \\
\hline $21-30$ & 94 & 09 & 103 & 31.31 & & \\
\hline $31-40$ & 46 & 04 & 50 & 15.19 & & \\
\hline $41-50$ & 26 & 06 & 32 & 9.73 & $28.08 \pm 14.77$ & $P<0.05^{\star}$ \\
\hline $51-60$ & 19 & 04 & 23 & 6.99 & & \\
\hline $61-70$ & 07 & 00 & 07 & 2.13 & & \\
\hline$>70$ & 02 & 00 & 02 & 0.61 & & \\
\hline Total & $274(83.28)$ & $55(16.72)$ & 329 & 100 & & \\
\hline
\end{tabular}

Values in parenthesis are percentage. $\mathrm{SD}=$ Standard deviation. ${ }^{\star}$ Refers to statistically significant result

Table 2 Sex-wise distribution and etiology of trauma

\begin{tabular}{lcccccc}
\hline $\begin{array}{l}\text { Etiology of } \\
\text { trauma }\end{array}$ & $\begin{array}{c}\text { Accidental } \\
\text { falls }\end{array}$ & Assault & $\begin{array}{c}\text { Road Traffic } \\
\text { Accidents (RTAs) }\end{array}$ & Others & Total & $P$ value \\
\hline Male & $21(6.38)$ & $20(6.08)$ & $226(68.69)$ & $07(2.13)$ & $274(83.28)$ & $0.255^{*}$ \\
Female & $06(1.82)$ & $08(2.43)$ & $40(12.16)$ & $01(0.30)$ & $55(16.72)$ & $329(100)$ \\
Total & $27(8.21)$ & $28(8.51)$ & $266(80.85)$ & $08(2.43)$ & \\
\hline
\end{tabular}

Values in parenthesis are percentage. ${ }^{\star}$ Refer to non-significant statistical value 
Table 3 Maxillofacial fractures distribution among the study sample

\begin{tabular}{lcc}
\hline Site of fracture & Frequency & Percentage (\%) \\
\hline Mandibular fracture & 203 & 61.70 \\
Zygomaticomaxillary complex & 32 & 9.71 \\
fracture(ZMC) & 31 & 9.42 \\
Midface fracture & 18 & 5.47 \\
Mandibular \& Midface fracture & 14 & 4.26 \\
Mandibular \& Zygomaticomaxillary & & \\
complex fracture & 05 & 1.52 \\
Naso-Orbital-Ethmoid fracture & 23 & 7.00 \\
Panfacial fracture & 03 & 0.92 \\
Orbital fracture & 329 & 100 \\
Total & & \\
\hline
\end{tabular}

Table 4 Distribution of mandibular fractures according to anatomic site

\begin{tabular}{lcc}
\hline Anatomic site & Number of fractures & Percentage (\%) \\
\hline Condyle & 44 & 14.07 \\
Coronoid & 02 & 0.64 \\
Ramus & 02 & 0.64 \\
Angle & 55 & 17.57 \\
Body & 112 & 35.78 \\
Parasymphysis & 73 & 23.32 \\
Symphysis & 10 & 3.19 \\
Dentoalveolar & 15 & 4.79 \\
Total & 313 & 100 \\
\hline
\end{tabular}

Table 5 Distribution of maxillary fractures

\begin{tabular}{lcc}
\hline Anatomic site & Number of fractures & Percentage (\%) \\
\hline Le Fort I & 16 & 31.37 \\
Le Fort II & 11 & 21.57 \\
Le Fort III & 07 & 13.73 \\
Dentoalveolar & 17 & 33.33 \\
Total & 51 & 100
\end{tabular}

second, $103(31.31 \%)$ in the third, $50(15.19 \%)$ in the fourth, 32 (9.73\%) in the fifth, $23(6.99 \%)$ in the sixth, $07(2.13 \%)$ in the seventh, $02(0.61 \%)$ in the eighth decade. Pediatric (less than 18 years of age) fracture accounted for $28.27 \%(\mathrm{n}=93)$ of patients, and $2.74 \%(\mathrm{n}=9)$ was more than 60 years of age table 1 . Men were mostly affected than women in all age groups. The male to female ratio was 4.98:1. The $P$-value (0.0002) showed statistical significance between the different age groups and sex.

Etiology: The road traffic accidents was the most common $(n=266 ; 80.85 \%)$ etiology of maxillofacial trauma, followed by physical assault $(\mathrm{n}=28 ; 8.51 \%)$

\section{Distribution of maxillofacial fractures according to sex}

Female

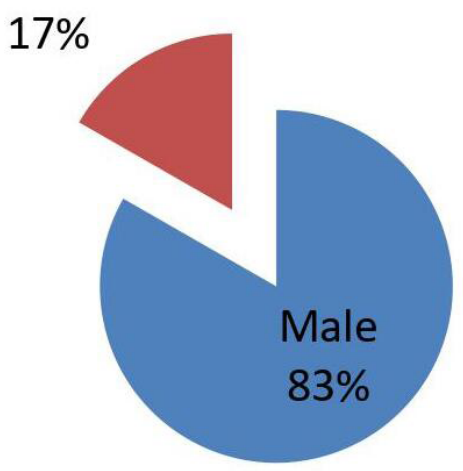

Figure 1 Shows the patient's distribution according to sex

\section{Etiology of trauma}

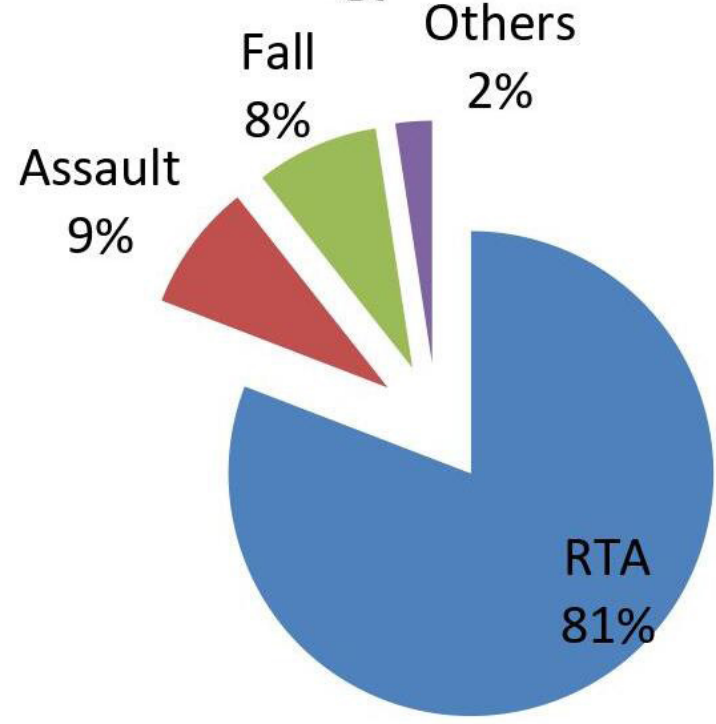

Figure 2 Shows the etiologies of maxillofacial trauma

and accidental falls ( $\mathrm{n}=27 ; 8.21 \%)$. The remaining fractures were due to a variety of causes, including sports-related injuries in 08 cases $(2.43 \%)$. The etiologies of injuries are shown in table 2 and figure 2. Our results showed no statistical significance between the genders regarding etiologies $(P=$ 0.255) of trauma.

Site of fractures: The mandible was most frequently fractured bone among the maxillofacial fractures. The mandibular fracture accounted for a total of 260 cases $(61.7 \%)$ with 313 fracture sites figure 3 and figure 4 . The 2nd most affected part of maxillofacial trauma was zygomaticomaxillary complex $(n=32,9.71 \%)$, figure 5 and it was followed by the midface $(n=31,9.42 \%)$, pan facial 


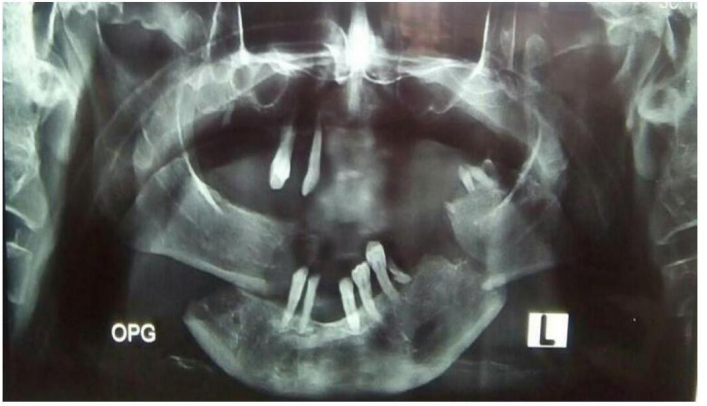

Figure 3 Orthopantomogram shows bilateral mandibular body fracture

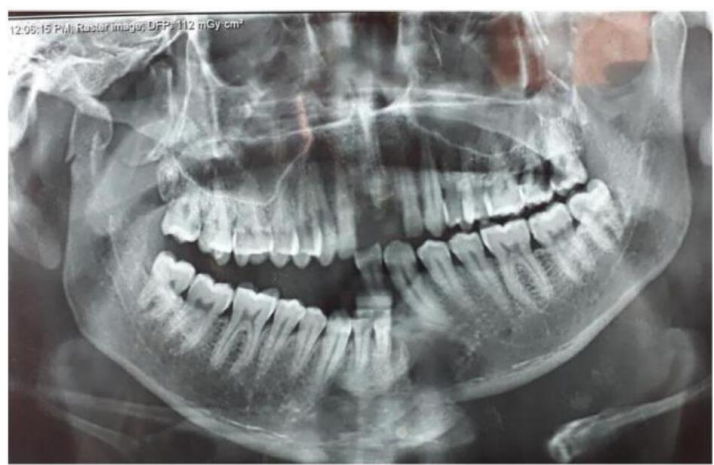

Figure 4 Orthopantomogram shows left parasymphysis and right subcondylar fracture of the mandible
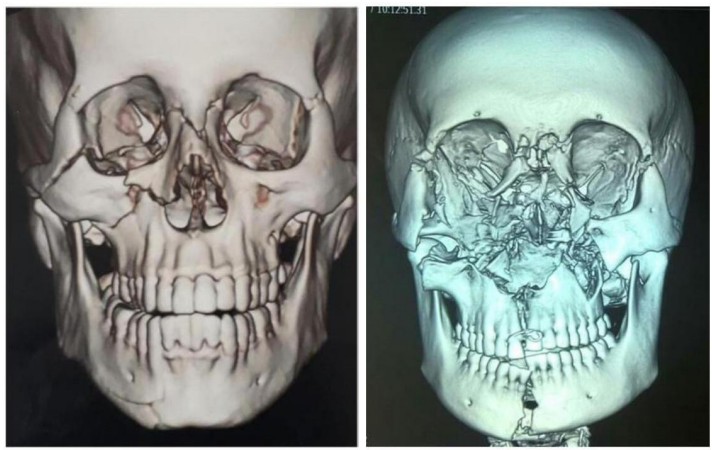

Figure 5 A. Three-dimension CT shows the right ZMC fracture, B. Three-dimension CT shows the pan-facial fracture

fractures $(n=23,7.00 \%)$, nasoethmoidal fractures $(\mathrm{n}=5,1.52 \%)$, orbital fracture $(\mathrm{n}=03,0.92 \%)$ as shown in table 3 . A total of 32 cases (11.25\%) were involved as a combination of fracture sites; of these 14 patients $(4.26 \%)$ had fractures of the mandible with zygomaticomaxillary complex (ZMC); 18 patients $(5.47 \%)$ had mandibular fracture along with midface table 3 . The distribution of the mandibular fractures is detailed in tables 4 . The most common site was the body $(35.78 \%)$ of the mandible, followed by parasymphysis (23.32\%), angle (17.57\%), condylar process (14.7\%), dentoalveolar process $(4.79 \%)$, symphysis $(3.19 \%)$, ramus $(0.64 \%)$, and the coronoid process $(0.64 \%)$. The distribution of maxillary fractures was Le Fort I in $16(31.37 \%)$, Le Fort II in $11(21.57 \%)$, Le Fort III in $07(13.73 \%)$, and the dentoalveolar process in 17 (33.3\%) cases table 5A and table 5B.

\section{Discussion}

There are considerable variations of the epidemiological studies regarding maxillofacial fractures. ${ }^{10}$ The incidence of maxillofacial injuries varies according to geographical conditions. It depends upon a variety of causative factors for example the ecological, cultural, social, and economic condition of the patient. ${ }^{11}$

In this study, we found the incidence of maxillofacial trauma mostly in the age group 21-30 years, which correlates with previous studies., ${ }^{3,11-13}$ The younger groups take part in outside activities such as exercises, games, automobile driving, and are probably to be involved in interpersonal aggressive activities. ${ }^{12}$ The mean age of the patient was $28.08 \pm 14.77$ years which was corroborated by other authors. ${ }^{12,13}$ The pediatric fractures accounted for $28.27 \%(n=93)$ contrary to the study of Agarwal et al. where it was $16.6 \%{ }^{12}$ The lowest frequency observed in the age group above 60 years $(2.74 \%)$ consistent with the results of Shah et al. ${ }^{12}$ and Agarwal et al. ${ }^{13}$ People with old age having less and controlled outdoor activities would be the probable cause. $^{12}$

Our study result showed that males were predominantly affected with a male to female ratio of 4.98: 1, which is consistent with other literature. $^{12,13}$ It is because men are mostly involved in outside deeds and are also exposed to brutal dealings. Moreover, Male drivers are predominant over females. $^{12}$

RTAs, physical assaults, and accidental falls are the primary causes of maxillofacial fractures globally. The major cause of fractures in males was RTAs ${ }^{3,12-15}$ and the present study supports these findings. Physical assault was reported as the major cause of maxillofacial fractures in England and China. ${ }^{16}$ The frequency of physical assault was $8.51 \%$ in our study. It is consistent with Shah et al. results. ${ }^{12}$ Accidental falls (8.21\%) were the $3 \mathrm{rd}$ common cause of maxillofacial trauma in our study findings.

The mandible is more susceptible than the mid-face fractures during maxillofacial trauma. ${ }^{6}$ The mandible is movable with less bony support than other midfacial bones, the reason behind the vulnerability of the mandibular fractures. We found the mandibular body as the predominant fracture site in our study. Shah et al. study concluded that the body of the mandible was the most frequently affected site in the mandibular fracture and the 
coronoid process as the least involved site. ${ }^{12}$ Our results correlate with Udeabor et al. study. ${ }^{17}$ In our study, we observed that the parasymphysis region of the mandible was the 2 nd most commonly involved site, which is in contrast with Shah et al. observation. Shah et al. reports revealed that the condylar region was the 2nd most-affected site of the mandibular fracture followed by angle and parasymphysis. ${ }^{12}$

The ZMC (9.71\%) was the most susceptible region in the midface fracture, followed by maxillary $(9.42 \%)$, pan facial fracture $(7.00 \%)$, nasoorbital-ethmoidal fractures $(1.52 \%)$, and orbital $(0.92 \%)$ fracture. Le Fort I (31.37\%) of maxillary fractures) and dentoalveolar fractures (33.33\%) of maxillary fractures) were the most common fractures among maxillary fractures. These findings are consistent with previously published reports. ${ }^{3,17}$

\section{Conclusion}

Maxillofacial trauma is one of the serious health issues in Bangladesh. Maxillofacial fractures lead to an esthetic and functional problem if it is not treated timely and properly. The consequences of trauma have an impact on the patient's psychology as well as lead to a socioeconomic burden. The highest incidence of maxillofacial fractures in our study was within the age group of 21-30 years old (31.31\%). The most frequent etiology was road traffic accidents (80.85\%) in the present study. The males were preponderant to females with a ratio of 4.98:1 in our study. Our study showed the predominance of mandibular fracture (61.7\%) among maxillofacial trauma patients. The body (35.78\%) of the mandible was the most frequent site followed by the parasymphysis region $(23.32 \%)$. The zygomaticomaxillary complex was the most fractured site (34.04\% of midface) in the midface. The findings of our study revealed that road traffic accidents were the major cause of maxillofacial injuries in Bangladesh. The awareness of the public particularly drivers about the significance of restrictions and protective measures in motor vehicles, ought to be executed by campaigning. These findings ought to caution the authorities to the need for the enforcement of existing traffic regulations to control careless high- speed driving on highways.

\section{Acknowledgment}

None.

\section{References}

1. Bither S, Mahindra U, Halli R, et al. Incidence and pattern of mandibular fractures in rural population: a review of 324 patients at a tertiary hospital in Loni, Maharashtra, India. Dent Traumatol 2008;24: 468- 470.

2. Olusanya A, Adeleye A, Aladelusi T, et al. Updates on the epidemiology and pattern of traumatic maxillofacial injuries in a Nigerian University Teaching Hospital: A 12-month prospective cohort in-hospital outcome study. Craniomaxillofac Trauma Reconstr 2015;8: 50- 58.

3. Tugaineyo E, Odhiambo W, Akama M, et al. Aetiology, pattern and management of oral and maxillofacial injuries at Mulago national referral hospital. East Afr Med J 2012;89: 351- 358

4. Adi M, Ogden G, Chisholm D. An analysis of mandibular fractures in Dundee, Scottland (1977 to 1985). Br J Oral Maxillofac Surg 1990;28: 194- 199.

5. Kyrgidis A, Koloutsos G, Kommata A, et al. Incidence, aetiology, treatment outcome and complications of maxillofacial fractures. A retrospective study from Northern Greece. J Cranio- Maxillofac Surg 2013;41: 637- 643.

6. Boffano P, Roccia F, Zavattero E, et al. European Maxillofacial Trauma (EURMAT) project: A multicentre and prospective study. J Cranio-Maxillofac Surg 2015;43: 62- 70 .

7. Oruç M, Işik V, Kankaya Y, et al. Analysis of fractured mandible over two decades. J Cranio-Maxillofac Surg 2016;27: 1457- 1461 .

8. Agarwal P, Mehrotra D, Agarwal R, et al. Patterns of maxillofacial fractures in Uttar Pradesh, India. Craniomaxillofac Trauma Reconstr 2017;10: 48- 55.

9. Singaram MGS, Udhayakumar R. Prevalence, pattern, etiology, and management of maxillofacial trauma in a developing country: a retrospective study. J Korean Assoc Oral Maxillofac Surg 2016;42: 174.

10. Hächl O, Tuli T, Schwabegger A, et al. Maxillofacial trauma due to work-related accidents. Int J Oral Maxillofac Surg 2002;31: 90- 93.

11. Ahmed H, Jaber M, Abu-Fanas S, et al. The pattern of maxillofacial fractures in Sharjah, United Arab Emirates: A review of 230 cases. Oral Surg, Oral Med, Oral Pathol, Oral Radiol, and Endodontol 2004;98: 166- 170.

12. Shah A, Bangash Z, Khan T, et al. The pattern of maxillofacial trauma \& its management. J Dent Oral Disord Ther 2016;4: $1-6$.

13. Agarwal P, Mehrotra D, Agarwal R, et al. Patterns of Maxillofacial Fractures in Uttar Pradesh, India. Craniomaxillofac Trauma Reconstr 2017;10: 48- 55.

14. Ansari M. Maxillofacial fractures in Hamedan province, Iran: a retrospective study (1987-2001). J Cranio-Maxillofac Surg 2004;32: 28- 34.

15. Ugboko V, Odusanya S, Fagade O. Maxillofacial fractures in a semi-urban Nigerian teaching hospital. Int J Oral Maxillofac Surg 1998;27: 286- 289.

16. Mijiti A, Ling W, Tuerdi M, et al. Epidemiological analysis of maxillofacial fractures treated at a university hospital, Xinjiang, China: a 5-year retrospective study. J CranioMaxillofac Surg 2014;42: 227- 233.

17. Udeabor S, Akinbami B, Yarhere K, et al. Maxillofacial fractures: etiology, pattern of presentation, and treatment in University of Port Harcourt Teaching Hospital, Port Harcourt, Nigeria. J Dent Surg 2014;2014: 1- 5.

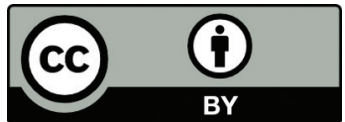

This work is licensed under a Creative Commons Attribution

\section{Conflict of Interest}

The authors report no conflicts of interest. 